\title{
Beijing Tongzhou (China) Logistics Base of the Development Countermeasure Research Based on the Coordinated Development of Beijing-Tianjin-Hebei
}

\author{
Dou Xin-xin, Wang Xiao-ping \\ School of Logistics, Beijing Wuzi University, Beijing, China \\ Email address: \\ 1185313260@qq.com (Dou Xin-xin),bjwxp2004@163.com (Wang Xiao-ping)
}

\section{To cite this article:}

Dou Xin-xin, Wang Xiao-ping. Beijing Tongzhou (China) Logistics Base of the Development Countermeasure Research Based on the Coordinated Development of Beijing-Tianjin-Hebei. International Journal of Business and Economics Research. Vol. 5, No. 4, 2016, pp. 95-100. doi: 10.11648/j.ijber.20160504.13

Received: July 6, 2016; Accepted: July 16, 2016; Published: August 2, 2016

\begin{abstract}
The core of the coordinated development of Beijing-Tianjin-Hebei is logistics integration of the Beijing-Tianjin-Hebei region. THE function adjustment of Beijing-Tianjin-Hebei, for the development of logistics industry, will bring great changes. In Beijing-Tianjin-Hebei regional logistics cluster development, the Beijing municipal function of the logistics park will also make major adjustments to adapt to the new environment. Taking logistics base in Tongzhou pony bridge as an example, through the SWOT analysis method, the analysis of the advantages and the disadvantages, on the basis of logistics base for the pony bridge development put forward the corresponding countermeasure and the suggestion, also for the future of Beijing under the background of the coordinated development of Beijing-Tianjin-Hebei logistics base development for reference.
\end{abstract}

Keywords: The Coordinated Development of Beijing-Tianjin-Hebei, Logistics Integration, Logistics Base, SWOT Analysis

\section{Introduction}

Under the background of the national promoting the new urbanization, accelerating the economic transformation and upgrading, comprehensively deepen reform, Beijing-Tianjin-Hebei coordinated development is put forward under the background of the current, the coordinated development of the Beijing-Tianjin-Hebei region, has risen to national development strategy, on February 26, 2014, the CPC central committee general secretary and President Xi Jinping held the Beijing-Tianjin-Hebei collaborative development symposium in Beijing, the meeting with Beijing-Tianjin-Hebei accelerate coordinated development as the theme. Coordinated development of the Beijing-Tianjin-Hebei region, the core is the coordinated development of Beijing-Tianjin-Hebei places as a whole, to ease core functions the capital, and solving the Beijing "big city disease" as the basic starting point, adjusting and optimizing the city layout and space structure, building a modern traffic network system, promoting industrial upgrading, efforts to form the Beijing-Tianjin-Hebei and the goal of the same direction, measures, complementary advantages, mutual benefit and win-win cooperation in the development of new pattern.
How to deal with the effects of the coordinated development of Beijing-Tianjin-Hebei logistics in Beijing? Breaking administrative division limit, guiding the cross-regional integration of logistics resources and optimize configuration, realizing the logistics integration of the Beijing-Tianjin-Hebei region, is the objective need of modern logistics industry development, also is the coordinated development of Beijing-Tianjin-Hebei important action.

In logistics integration of the Beijing-Tianjin-Hebei region, in the process of the development of Beijing is not only to make full use of existing resources, and the optimization of logistics resources for scientific and reasonable configuration, at the same time of improving Beijing's logistics environment, to better serve the Beijing-Tianjin-Hebei environment. "Here refers to" the logistics resources, mainly urban logistics resources, only refers to the coordinated development of Beijing-Tianjin-Hebei related logistics resources, which not only service the logistics industry in Beijing, radiation Beijing-Tianjin-Hebei both and even the whole country, also have important influence on the coordinated development of Beijing-Tianjin-Hebei logistics resources. There are lots of the relevant factors affecting the development of 
Beijing-Tianjin-Hebei logistics integration, this paper takes Beijing Tongzhou logistics bases as the research object, to explore under the background of the coordinated development of Beijing-Tianjin-Hebei, the logistics base, the new development direction in Beijing, to achieve the optimal allocation of logistics resources of Beijing.

\section{Logistics Base}

National standard "logistics term" (GB/T18354-2006), explaining "logistics base" concept as follows: logistics base is a very large logistics node, its intensive function is very strong, its comprehensive function is very strong, it is the product of a few small intensive integration of logistics node; And common intersection of different logistics routes. Logistics base is one or more of the logistics center and distribution center focused on the space layout of the site, and have a certain scale and the comprehensive service functions of logistics rally point. It faces the society to provide professional services, logistics distribution of urban or regional commercial circulation with a backbone role, logistics base should have such characteristics: comprehensive intensive, independent and professional, and public commonweal.

Beijing vigorously develop the logistics base, first of all, can promote regional economic development, the development of the logistics base and construction, will encourage the generation of new economic growth point, improve the logistics environment, cultivate logistics industry, thus have radiation effects on regional economy and cluster effect; Secondly, it can promote the development of the logistics industry, logistics base can integrate the existing resources to form the logistics industry in the process of development, and at the same time, the logistics base for existing enterprises provide a good space for development, to help their healthy development; Third, it can optimize the urban structure and environment, through to the logistics base, scientific planning and site selection, not only can improve traffic conditions, can improve the urban land structure [1].

\section{Beijing Tongzhou Logistics Base of SWOT Analysis}

\subsection{Beijing Tongzhou Logistics Base Introduction}

Beijing Tongzhou logistics base was established by the Beijing municipal government in January 22, 2002, formally approved as the establishment of city development zone. Meanwhile, it is one of the three large logistics base in Beijing, which confirmed by Beijing Business Logistics development at the "tenth five-year plan", planning area of 5.04 square kilometers. Base collection of modern logistics, inland port, circulation processing functions into an organic whole, is to adapt to the modern international metropolis, the capital of functional infrastructure, radiation link Bohai (China) sea area and the national important transport hub, in and out of the distribution of goods to Beijing, and the large manufacturers in the Bohai sea area, the procurement and distribution logistics platform, located in the road - shipping international freight hub type logistics base [2].

Beijing Tongzhou logistics base is located in the southeast of Beijing, Beijing is the heart of internal and external transportation hub, mainly to undertake by sea and the Bohai sea region of Beijing international and domestic shipping logistics functions, key services in Beijing southeast of JingJinTang (Beijing-Tianjin-Tangshan) economy development belt, serve as well economic technique development zone, is a major hub of Beijing for inbound or outbound goods [3]. JingJinTang expressway and Beijing six loop at the intersection, and with the Beijing-Shenyang, JingHa, JingKai expressway, zone bit and traffic advantages is outstanding, has provided a broad space for development of modern logistics industry. Location as shown in the Figure 1.

Beijing Tongzhou logistics base relys on Beijing's industrial advantages, talent advantage, information advantage, build a logistics information platform, building modern logistics base. Base infrastructure adhere to a high starting point, standardization, scale, networking, internationalization of standards development and construction, will implement the "ten connection and one leveling", for the development of the logistics enterprises to build the international first-class platform [4]. Logistics base development and construction, there have been many companies into a base, build the good environment for the development of logistics industry, formed the modern logistics technology, information, equipment, personnel, management, resources, customer accumulative effect, promote the socialization of the logistics industry, modern, intensive and professional development, makes the modern logistics enterprises there is a sustained, rapid and healthy development depends on the carrier.

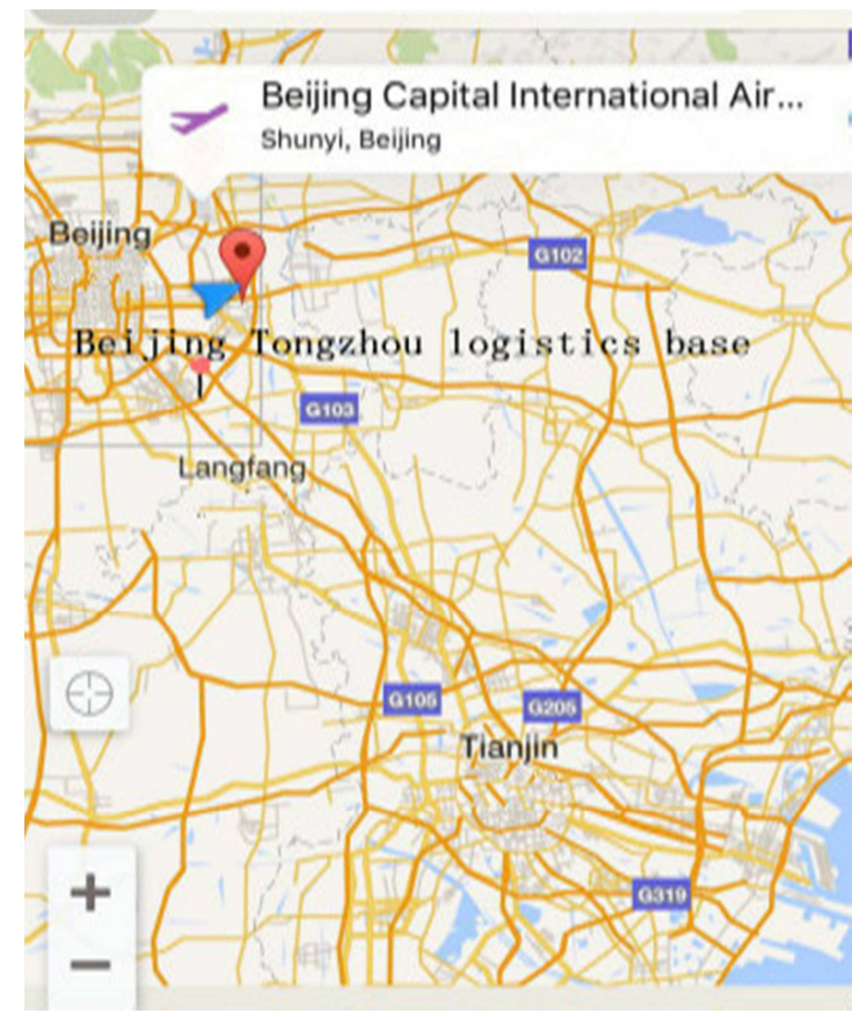

Figure 1. Beijing Tongzhou logistics base bearing figure. 


\subsection{SWOT Analysis}

SWOT analysis (also called TOWS analysis, dawes matrix) is situational analysis, in the early 1980s, proposed by Wally, the professor of management at the university of San Francisco, is often used to make enterprise strategy, competitor analysis and so on occasion [5].

The so-called SWOT analysis, based on internal and external competition environment and competition under the condition of situational analysis, is closely related to the object of study of various main internal strengths, weaknesses and external opportunities and threats, and so on, through the investigation list, and according to the matrix form, and then use the thought of system analysis, the various factors each other match analysis, from which a series of corresponding conclusions, and the conclusion is usually a certain decision-making. S (strengths), $\mathrm{W}$ (weaknesses) is the internal factor, $\mathrm{O}$ (opportunities), $\mathrm{T}$ (threats) is the external factors. According to the enterprise competition strategy complete concept, strategy should be a enterprise "can do" (that is, the organization's strengths and weaknesses) and "may do" (environment opportunities and threats) between organic combination [6].

\subsection{Beijing Tongzhou Logistics Base of SWOT Analysis}

\subsubsection{Economical Environment Analysis}

Beijing's function orientation is weakening economic center, continuously in adjustment of industrial structure, but in Beijing as an international metropolis, its economic environment influence is very big still. Table 1 is the fiscal revenue of Beijing Tongzhou district in 2012 and 2011, also the tax of Tongzhou logistics base and the proportion of comprehensive comparison table. What we can intuitively see from table is Tongzhou logistics base tax value of Tongzhou district presents a tendency of increasing financial income proportion, year-on-year growth of $37.55 \%$; Tongzhou logistics base tax accounted for four big logistics base proportion also shows ascendant trend, up $17.30 \%$ from a year earlier.

Table 1. Comprehensive comparison table.

\begin{tabular}{lllllll}
\hline & $\begin{array}{l}\text { Tongzhou } \\
\text { district revenue } \\
\text { iten thousand } \\
\text { yuan) }\end{array}$ & $\begin{array}{l}\text { Beijing Tongzhou } \\
\text { logistics base } \\
\text { output (ten } \\
\text { thousand yuan) }\end{array}$ & $\begin{array}{l}\text { Beijing Tongzhou } \\
\text { logistics base } \\
\text { represented (ten } \\
\text { thousand yuan, in the } \\
\text { first three quarters) }\end{array}$ & $\begin{array}{l}\text { Four big logistics base } \\
\text { always represented } \\
\text { (ten thousand yuan, in } \\
\text { the first three } \\
\text { quarters) }\end{array}$ & $\begin{array}{l}\text { Beijing Tongzhou } \\
\text { logistics base, } \\
\text { Tongzhou } \\
\text { revenue } \\
\text { proportion tax }\end{array}$ & $\begin{array}{l}\text { The proportion } \\
\text { of Tongzhou } \\
\text { logistics base of } \\
\text { four logistics base }\end{array}$ \\
\hline 2012 & 1105321 & 1600000 & 70000 & 131500 & $6.30 \%$ & $53.23 \%$ \\
2011 & 1223642 & 1280000 & 56000 & 123400 & $4.58 \%$ & $45.38 \%$ \\
amplification & $-9.70 \%$ & $25 \%$ & $25 \%$ & $6.05 \%$ & $37.55 \%$ & $17.30 \%$ \\
\hline
\end{tabular}

the above datas is from Beijing municipal bureau of statistics

Tongzhou logistics base attached to Beijing development planning, and its output value and the local regional fiscal income is positive correlation, the unique set of source advantage provides many opportunities for the development of Tongzhou logistics base, this is the Tongzhou logistics base, logistics base for the development of advantages compared to other regions; Beijing function will adjust to a certain extent influence the development of the enterprise, it will also spread to the whole logistics industry of Beijing, If Tongzhou logistics base fail to meet the market positioning, so the adjustment of the industrial chain would threaten the development of Tongzhou logistics base [7].

\subsubsection{Political Environment Analysis}

Under the background of the coordinated development of Beijing-Tianjin-Hebei, Beijing Tongzhou logistics base deep in the transportation hub in Beijing, policy influence the most aggressive. For the development of the logistics industry, Beijing has launched a lot of guidance documents, such as "overall planning of Beijing", "the logistics industry adjust and revitalization of planning", "The logistics industry development planning with Beijing twelfth five-year period," etc. All kinds of policies are the development of Tongzhou logistics base provides a good environment for development and development opportunities, in the context of integration of the Beijing-Tianjin-Hebei region, more advantageous to realize the optimal allocation of resources and industrial docking [8].

But as the economic function is weakening, the Beijing-Tianjin-Hebei economic circle of the jintang will undertake part of the economic function of Beijing, the corresponding market function of logistics enterprises to adjust, also, in the upstream of the logistics base of the market function will also change, so the economic effects of policy changes for Tongzhou logistics base development, is a challenge.

\subsubsection{Traffic Environmental Analysis}

The eleventh five-year plan of Beijing development has proposed the new space layout, and supported infrastructure for the Beijing international logistics, regional logistics and the development of urban logistics. The logistics base is located in Tongzhou district, JingJinTang expressway east, south of six ring, sevred as shipping - road - port international freight hub type logistics base, unique natural geographical advantage has produced for Beijing Tongzhou logistics base for the main hub of inbound and outbound goods.

Huge traffic volume of Beijing is also an expression of the "big city disease", Tongzhou logistics base can realize the control of the transport vehicle is the key to solve the "big city disease". Haze as a model environmental issues outstanding, also have already been included in the planning of Beijing, green travel of Tongzhou logistics base has becomed a challenge for the future development [9]. 


\subsubsection{Logistics Base Condition Analysis}

(1) General situation. Tongzhou logistics base project introduction work actively continue, putting forward ten headquarters "logistics" development train of thought. Successively introduced many famous companies such as the SuNing appliance, HengRi machinery, China merchants logistics, currently in entity, with the total investment more than 50 enterprises, attracting more than 100 registered enterprises, total investment of more than 10 billion yuan, area storage area has reached 400000 square meters, existing goods storage and distribution volume reached 3 million tons.

(2) Business projects. Mainly for the Beijing Tongzhou logistics base in and out of goods to provide a platform for procurement, distribution, built set inland port, goods distribution, circulation processing functions, goods distribution, and other functions in one of the "large comprehensive modern logistics hub". Logistics is the main form of freight charge, \&highway combined, the information of goods loading, loading of goods. Tongzhou logistics bases as a pass-through of Tianjin port, the burden of a large concentration of import and export goods transport. But some do not have a high level of modern logistics enterprises, supporting facilities is not perfect, single function, combining business with less-than-one carload express and vehicle distribution.

(3) Information technology application. Dominated by phone contact most of the logistics enterprises, logistics information collection, processing, processing, transfer is not controllable factors, logistics information utilization and low efficiency, enterprises lack of logistics professionals, the single management mode.

(4) Development mode and development space. Early development stage logistics base covers an area of larger scale and funds, Tongzhou logistics base's marketization operation model, namely by the base for the development of the subject company solve the problem of funds through bank loans, this will increase the burden of base. In addition, look from the development trend, the current base of land has already can't meet the future development, need to consider the problem of expanding area, the land problem is always the bottleneck of enterprise development.

Summary for the development of Tongzhou logistics base environment advantage, have disadvantage, opportunities, threats, specific details are shown in Table 2.

Table 2. Tongzhou logistics base of SWOT analysis.

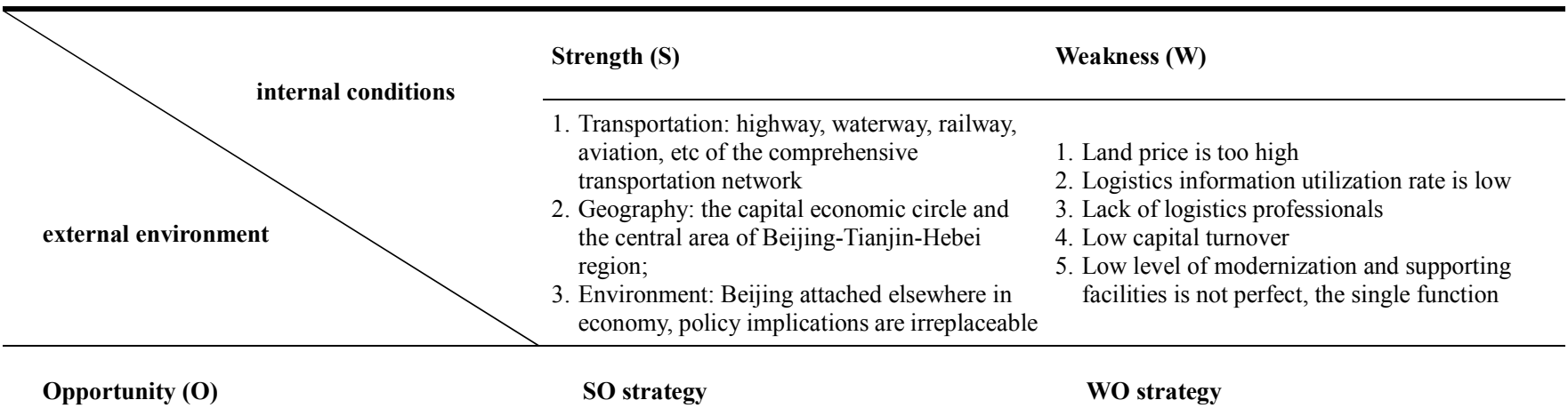

1. The national development wisdom logistics environment

2. Integration of the Beijing-Tianjin-Hebei region development planning

3. Tongzhou economic development needs

4. The Beijing municipal government policy guidance

5. Improve the increasingly serious traffic congestion and environmental pollution are urgently needed

6. Other areas of the lack of planning, logistics activities scattered and information single
1. Make full use of the transport hub advantage and policy guidance, adjust base scope of radiation

2. Strengthening logistics park of butt joint and the Beijing-Tianjin-Hebei region, including personnel, logistics flow logistics resources, facilities, equipment, etc

3. Based in Beijing, for the service of the Beijing-Tianjin-Hebei region, green travel
1. Negotiation with the ministry of commerce, land planning bureau of Beijing, decentralized operation cost

2. training and the introduction of logistics professionals, enrich the logistics management and operation team

3. make full use of talents, industries and policy advantage of Beijing 4 perfect supporting facilities, promote the development of industrial clusters

\section{Threat (T)}

\section{WT strategy}

1. reposition function of Beijing, industrial adjustment

2. continues the saturation of the Beijing-Tianjin-Hebei region logistics resources,

3. competition development integration of the Beijing-Tianjin-Hebei region function transfer cycle is long
1. Timely follow up the process of industry adjustment, adjust the positioning base

2. with Tianjin-Hebei coordinated development, avoid vicious competition

3. use the function to adjust time, seize the development direction
1. Pays special attention to the construction of logistics infrastructure, improve the logistics information network

2. government guide, regulate, support and cultivate the scale logistics enterprises 


\section{Development Strategy of Tongzhou Logistics Base}

Deep base in southeast of Beijing Tongzhou logistics transportation hub, its advantageous geographical location for logistics base has brought a lot of big located enterprises also pull some of the industry economic growth. Under the background of the coordinated development of Beijing-Tianjin-Hebei, Tongzhou logistics base and at the same time show the need to adjust the development direction of:

\subsection{Serve Beijing-Tianjin-Hebei and Common Development}

Tongzhou logistics bases as radiation bohai rim region and the national important logistics hub, its carrying bulk cargo transport function, Hebei, Tianjin logistics base should be increased and the Beijing-Tianjin-Hebei region logistics park of docking dynamics, including personnel, logistics flow, facilities and other logistics resources; Beijing-Tianjin-Hebei coordinated development, and avoid vicious competition; Highlight the characteristics and differences between development of Tongzhou logistics base should be giving full play to the advantages of road - shipping international freight hub, towards the bulk cargo distribution center with the most complete functions in the circum bohai sea region development.

\subsection{Use of Science and Technology, and Efficient Development}

Beijing has good information, industry, talent resources, Tongzhou logistics base should make full use of these advantages, pays special attention to the construction of logistics infrastructure, perfect the construction of logistics information network, in addition to the introduction of advanced equipment, should strengthen the cultivation of talents and recruiting, Tongzhou logistics base by logistics operations, information technology and professionals for occupancy and upstream and downstream enterprises and related customers with higher quality of service, let Tongzhou logistics base in the environment can better and faster development.

\subsection{Ecological Barrier, Green Development}

Under the background of the coordinated development of Beijing-Tianjin-Hebei, all industry's development is inseparable from the protection of ecological environment, otherwise will be eliminated by social mechanism. Tongzhou logistics base to build "green" in the capital circle for docking hub, in line with "green travel", the purpose of the vehicle scheduling plan, avoid traffic congestion; In terms of vehicle emissions, the introduction of high technology processing equipment, reduce air pollution.

\subsection{Policy Support, Healthy Development}

From the development trend, the Tongzhou logistics base land has already can't meet the future development, need to consider the problem of expanding area, in order to avoid the base in the process of expansion of large investment, long construction period, with slow, you will need to the government in financing, tax, land policy tilt, preferential and support for the parties, such as; Establish special start-up capital at the same time, intensify efforts to support the expansion of the Tongzhou logistics base.

\section{Conclusion}

In this article, through the SWOT analysis method, the Beijing Tongzhou logistics base from the perspective of economy, politics, transportation, enterprise under the background of the integration of the Beijing-Tianjin-Hebei region, the strengths, weaknesses, opportunities, threats, factor analysis, summed up the Beijing Tongzhou logistics base further development direction and development.

In Beijing Tongzhou logistics base is the important base in the planning of logistics base, it also represents the future of the trend of future development of logistics park in Beijing. To achieve the optimal allocation of logistics resources in Beijing, then you must start affect economic development and people's livelihood node optimization, the series of changes brought by the integration of the Beijing-Tianjin-Hebei region, the influence of the whole logistics industry of Beijing, Beijing logistics industry to make timely adjustment, to avoid the logistics resource waste, avoid the waste of resources is also the focus of the resource optimization [10].

Concept of collaborative development of the BeijingTianjin- Hebei region, not only affects the Beijing- TianjinHebei adjustment, the three areas of the industry chain for north China region and even the whole China's industry development provides opportunities and challenges.

\section{Acknowledgements}

This is the social science fund research base project of Beijing-Beijing logistics resources optimization allocation in the coordinated development of Beijing-Tianjin-Hebei research (project number: 15 jdjgb 054) research.

\section{References}

[1] Liang Chen, Yang Yang, Wang Xiaochun. $<<$ Logistics park planning $>>$, $[\mathrm{M}]$. Beijing: China Fortune publishing house, 2013, 08-09

[2] Yang Lei. Market positioning of logistics park in Tongzhou, Beijing [J]. public science and technology, 2005, 86 (12): 209-210

[3] Sun Qianjin. The distribution and functional orientation of Beijing logistics base [J]. business era, 2011, 78 (25): 30-40

[4] Li Faxin. The essence of service is not to say "no" to the world of [J]. transportation manager, 2011, 98 (04): 41-42 
[5] Li Jun, Zhang Na. Based on the SWOT analysis method to enhance the core competitiveness of China's high level research universities [J]. Institute of science and technology research, 2010, 29 (03): 06-10

[6] Le Shiting. Research on Xianning Tongshan logistics park construction with SWOT analysis [J]. Journal of Hebei Energy Institute of Vocational and Technology, 2015, 1 (57): 41-43

[7] Li Wenyi, Zhang Meiqing. Optimization of regional logistics development under the economic integration of Beijing, Tianjin and Hebei Province [J]. Economic Logistics, 2012, 10: 38-44

[8] Sun Yuexin, Yuan Mingming. Current situation of the integrated development of Beijing-Tianjin-Hebei [J]. Journal of Hebei Union University [J], 2015, 4 (15): 27-33

[9] Wang Xiuhua, Based on integrated Beijing-Tianjin-Hebei rail transport coordination and development research and prospect, the railway standard design [J], 2015, 6 (59): 1-5

[10] Li Zixiang. Research on the Beijing urban functions based on the integration of Beijing-Tianjin-Hebei, China Economic and Trade Herald [J], 2014, 8: 22-23

\section{Biography}
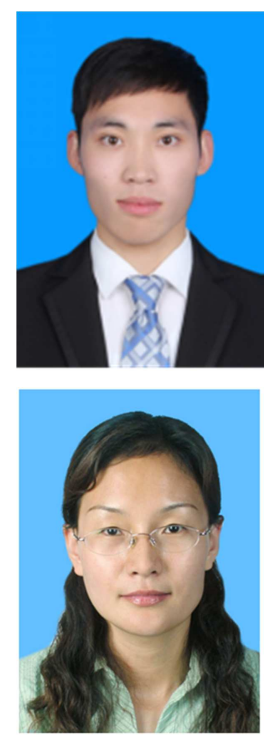

Wang Xiao-ping (1977-), female, shandong province, Associate professor and Associate Dean, of School of logistics, Beijing Wuzi University, Ph. D., main research direction for the logistics integration of the Beijing-Tianjin-Hebei region, logistics information, etc.

Dou Xin-Xin (1993-), male, hebei province, graduate student of Beijing Wuzi University, the main research direction for the logistics integration of the Beijing-Tianjin-Hebei region, the logistics park planning. 